\title{
EXPERIMENTAL ANALYSIS OF THE TRANSIENT BEHAVIOR OF AN ENGINE COOLING RADIATOR
}

\author{
K. Rodrigues ${ }^{\mathrm{a}}$, \\ J. P.S. Ieno ${ }^{a}$, \\ L. F. Novazzi ${ }^{\text {, }}$ \\ ABSTRACT \\ The aim of this work is to study the behavior of an engine cooling radiator \\ in a transient state, with circulation of heated water. An experimental \\ apparatus was constructed with the radiator inside a wind tunnel. The water \\ is pumped from a small water tank to a heater, passes through the heat \\ exchanger, and returns to the tank. The tests were carried out with constant \\ flowrates of water and air, and the heater was turned on and then off \\ ${ }^{\mathrm{a}}$ Centro Universitário FEI \\ according to a pulse function. The temperatures of the radiator, the air and \\ the water were measured on several points with thermocouples and a \\ thermal camera. The flow of water and air were measured as well. A fast \\ dynamics because of the radiator was observed, whereas a slow one was \\ noticed due to water heating in the tank. The steady state was reached after \\ $15 \mathrm{~min}$. These results might be useful in the project of a vehicle cooling \\ system under transient conditions. \\ Departamento de Engenharia Mecânica \\ São Bernardo do Campo, SP, Brasil \\ CEP 09850-901 \\ cyroan@fei.edu.br \\ ${ }^{\mathrm{b}}$ Centro Universitário FEI \\ Departamento de Engenharia Química \\ São Bernardo do Campo, SP, Brasil \\ CEP 09850-901 \\ Received: April 14, 2018 \\ Revised: June 18, 2018 \\ Accepted: October 18, 2018 \\ Keywords: heat exchanger; radiator; heat transfer; transient analysis
}

\section{NOMENCLATURE \\ $\mathrm{kg} \cdot \mathrm{s}^{-1} \quad$ Air or water mass flow \\ $\mathrm{kW} \quad$ Heater power \\ L Water tank volume}

\section{INTRODUCTION}

Any electric or internal combustion engine in operation releases heat, generated by the friction between the components, by the passage of electric current, combustion, among others. This heat must be rejected to the environment, either by the exhaust gases and by a subsystem which contains the heat exchanger know as radiator. Basically, the radiator is a cross flow compact heat exchanger that is composed by flat tubes with louvered fins between them. The flow of air from the vehicle displacement passes through the radiator, which has fins positioned transversely to the airflow. The fluid after exiting the engine loses heat as it passes through the tubes that are in contact with the fins, and returns to the engine.

The process for designing an automotive heat exchanger is similar for passenger, freight or competition vehicles, but there are important peculiarities in each project that need to be observed, as well as the presence of turbocharged, automatic transmission or air conditioning, and the maximum and minimum ambient temperatures.

The study of a radiator in a transient state is important because a vehicle is usually changing its state, such during acceleration, resulting in different heat rejections and air flow conditions. Besides, due to the nonuniformity of fluids temperatures on the transient state, the radiator performance and the heat transfer coefficients are affected as well.

Most of the studies of the transient behavior of heat exchangers deal with models for simulation (Mishra et al., 2006; Korze'n and Taler, 2015; Vaisi et al., 2011). The transient analysis is often used to obtain heat transfer design data (Krishnakumar et al., 2011). In experimental studies with air, the heat exchanger is generally placed inside a wind tunnel (Wang et al., 2015; Glazar et al., 2015). Experimental analysis to obtain the heat transfer coefficients of an automotive radiator was carried out by Cuevas et al. (2011).

The aim of the present work is to study the transient behavior of a radiator inside a wind tunnel, when subjected to an increase in the heat supplied to the circulating water.

\section{EXPERIMENTAL PROCEDURE}

The radiator used in the tests is a typical model used in the automotive industry. It is made of aluminum with fins. It has 35 tubes with external area of $0.229 \mathrm{~m}^{2}$ and 36 rows of fins. Its main dimensions are presented in Fig. 1.

The radiator was placed inside a wind tunnel, 
ensuring that all the air passes through it. Figure 2 shows the experimental apparatus. The test section was made of acrylic to allow visualization, with holes for the insertion of the measuring instruments. The wind tunnel was manufactured at the institution. Without the radiator, it allows controlled air velocities of up to $34 \mathrm{~m} / \mathrm{s}$.

Water flows through a submerged pump inside a small water tank to a water heater, and then to the radiator. After leaving the radiator the water returns to the tank. The volume of water in the whole system (tank, radiator and pipes) was $3.5 \mathrm{~L}$, and the flow was set to $(4.75 \pm 0.01) \cdot 10^{-2} \mathrm{~kg} \cdot \mathrm{s}^{-1}$, measured by the time to fill a certain volume.
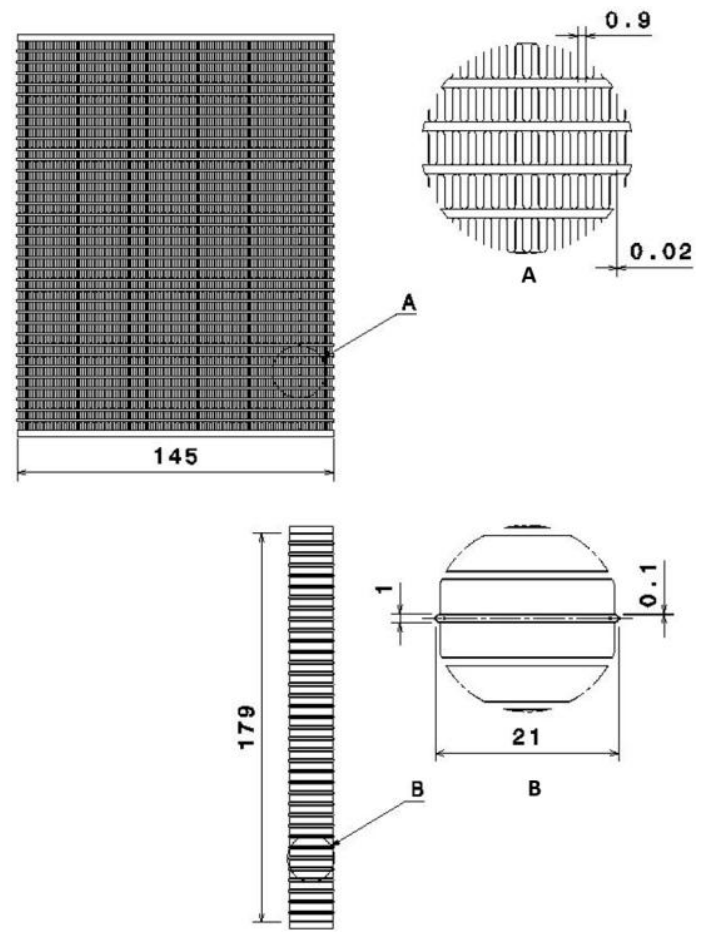

Figure 1. Details of the studied heat exchanger.

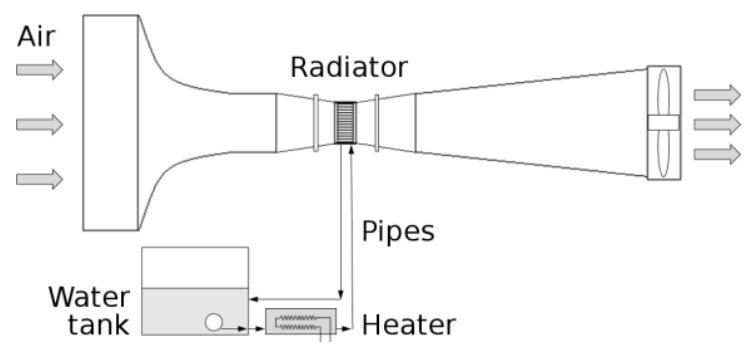

Figure 2. Experimental apparatus.

The power of the water heater was obtained by measuring the current and voltage with a multimeter (Minipa ET-3702A, True RMS, $\pm 2 \%$ accuracy).

The air flow was measured with a hot-wire anemometer (TESTO $405-\mathrm{V} 1$, accuracy of $0.1 \mathrm{~m} / \mathrm{s}+$ $5 \%$ of the measured value) at several points before the radiator. For the tests an air flow of $0.181 \pm 0.010$ $\mathrm{kg} \cdot \mathrm{s}^{-1}$ was selected.
Type $\mathrm{T}$ thermocouples (OMEGA, diameter $0.0762 \mathrm{~mm}$, limit of error $0.7^{\circ} \mathrm{C}$, verified at 20,40 , 60 and $80^{\circ} \mathrm{C}$ ) were placed to measure the inlet and outlet of water and air of the radiator, the water inside the tank, and the radiator surface. Due to the nonuniform temperature distribution of air after leaving the radiator, a net of 15 thermocouples was used (based on the works of Wang et al. (2015) and Glazar et al. (2015)). Data acquisition was performed by a National Instrument CompactDaq with 6 modules NI 9211. A thermal camera (FLIR T450sc) was also used during the tests to measure the radiator external temperature.

With constant water and air flowrates, a dynamic test was carried out by applying a pulse function in the heater: it was turned on until a steady state was reached and then it was turned off.

\section{RESULTS AND DISCUSSION}

In this test the heater was set to $(2.73 \pm 0.08) \mathrm{kW}$ and turned on and off at $1 \mathrm{~min}$ and $16 \mathrm{~min}$, respectively. Figure 3 shows the behavior of water / air inlet and outlet temperatures, heat exchanger average temperature and the temperature of the water inside the tank.

It may be noted that water temperature at the radiator inlet had a fast increase of $11{ }^{\circ} \mathrm{C}$ in the first $7 \mathrm{~s}$ seconds, and then increased slowly until steady state was reached, at $52.4{ }^{\circ} \mathrm{C}$. After turning off the heater, the temperature dropped fast reaching $40.4{ }^{\circ} \mathrm{C}$ in $4 \mathrm{~s}$, and then continued to drop moderately to room temperature. The water temperature at the radiator outlet had a similar behavior, but with a delay of about $2 \mathrm{~s}$ due to the passage across the radiator, reaching $40.3{ }^{\circ} \mathrm{C}$ in the steady state.

The fast temperature increase happens because of the fast dynamics of the radiator heat transfer, and the slow temperature increase is due to water heating inside the tank. A similar behavior is found when the heater is turned off. These results suggest that process time constants for the radiator and for the tank are equal to $1 \mathrm{~s}$ and $4 \mathrm{~min}$, respectively.

It is also worth noting that water and air outlet temperatures are almost equal, in virtue of the high efficiency of the radiator.

Figure 4 shows surface temperature distribution of the radiator during the test. The temperature difference from the right side of the equipment, where water flows in, to the left side, where water leaves, is evident. Moreover, it may be noted that the radiator reaches steady state nearly to $15 \mathrm{~min}$, corresponding to the values observed on Fig. 3.

\section{CONCLUSIONS}

In this work the transient behavior of a radiator was studied inside a wind tunnel. The experimental results showed that the radiator has a fast response when the water temperature is increased. If the heater 
remains on, the whole system starts getting warmer. The temperature of the water and the air leaving the radiator are very similar, both the heating and cooling periods. The difference in the temperature distribution of the radiator is observed from the water inlet side to the outlet side.
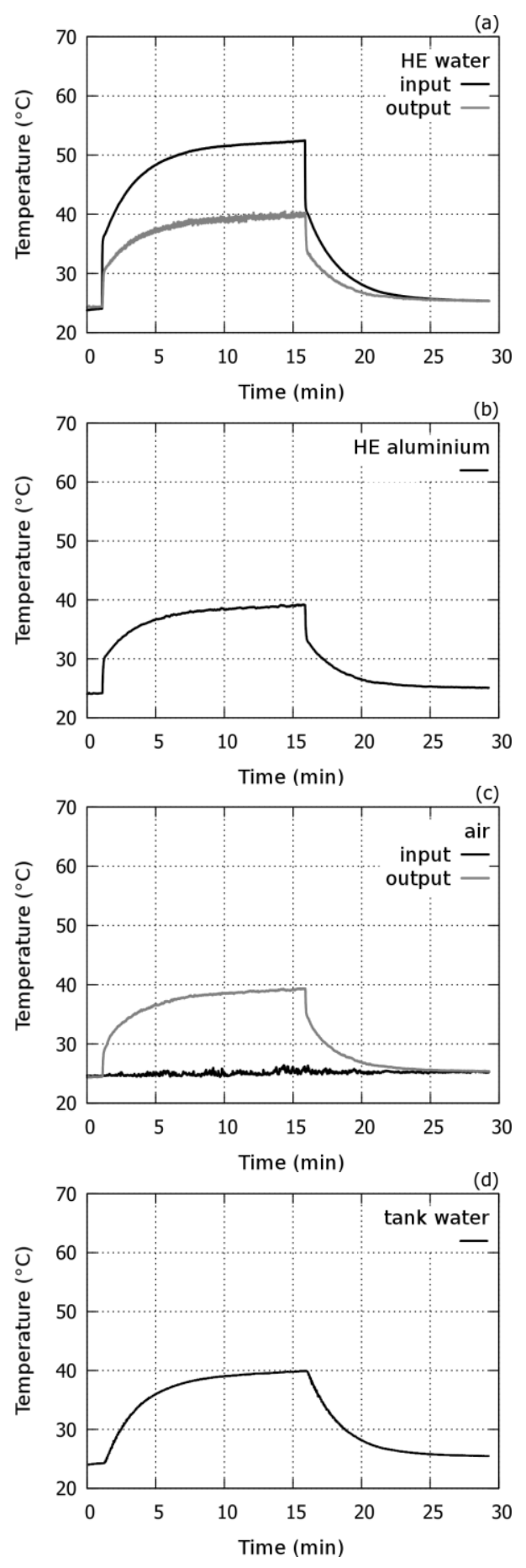

Figure 3. Temperature of the water in the inlet and outlet of the radiator (a), average temperature of the radiator aluminum (b), temperature of the air before and after passing through the radiator (c), and temperature of the water inside the tank (d) during the transient test.
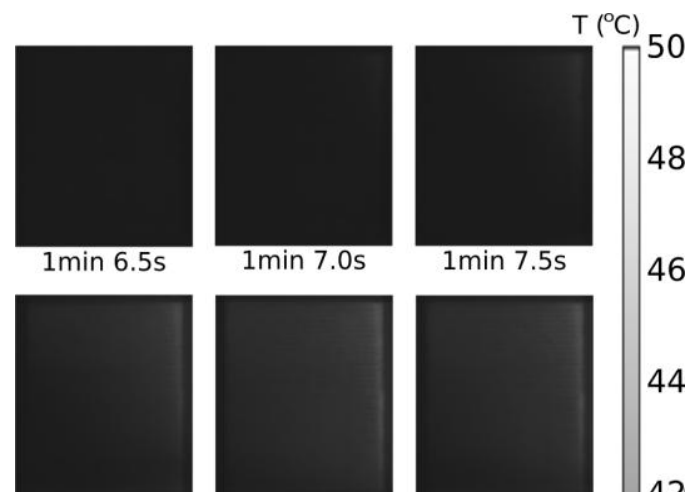

$1 \mathrm{~min} 7.0 \mathrm{~s}$

$1 \min 7.5 \mathrm{~s}$
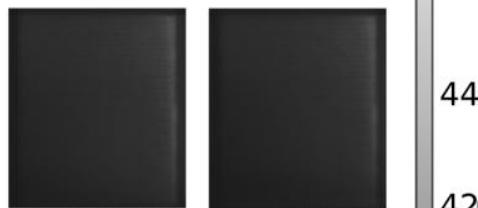

$1 \mathrm{~min} 9.0 \mathrm{~s}$

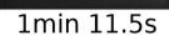

$1 \min 14.5 \mathrm{~s}$

42
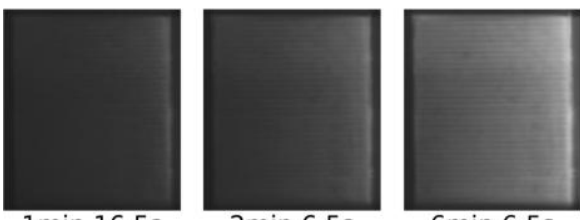

40

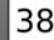

$1 \mathrm{~min} 16.5 \mathrm{~s}$

$2 \min 6.5 \mathrm{~s}$
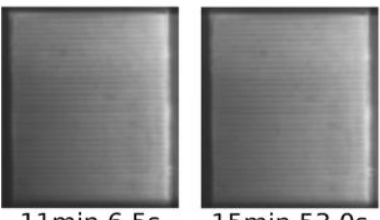

$6 \min 6.5 s$
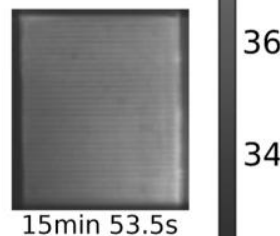

34

$11 \mathrm{~min} 6.5 \mathrm{~s}$
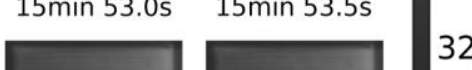

32
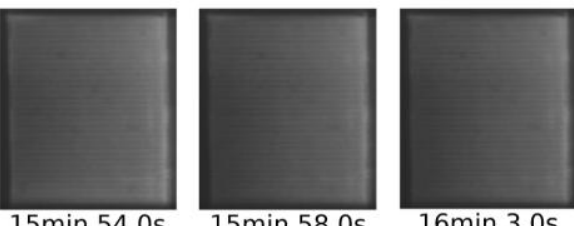

30

$15 \min 54.0 \mathrm{~s}$

$15 \mathrm{~min} 58.0 \mathrm{~s}$

$16 \mathrm{~min} 3.0 \mathrm{~s}$
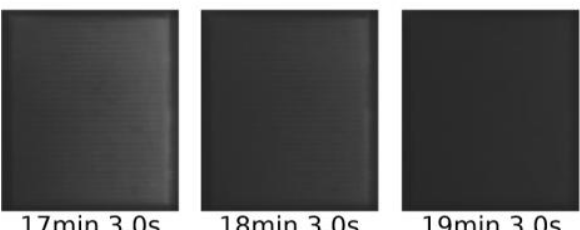

$17 \mathrm{~min} 3.0 \mathrm{~s}$

$18 \mathrm{~min} 3.0 \mathrm{~s}$

$19 \mathrm{~min} 3.0 \mathrm{~s}$

24

Figure 4. Surface temperature distribution of the radiator during the transient test.

\section{REFERENCES}

Cuevas, C., Makaire, D., Dardenne, L., and Ngendakumana, P., 2011, Thermo-Hydraulic Characterization of a Louvered Fin and Flat Tube Heat Exchanger, Experimental Thermal and Fluid Science, Vol. 35, No. 1, pp. 154-164.

Glazar, V., Frankovic, B., and Trp, A., 2015, Experimental and Numerical Study of the compact Heat Exchanger with Different Microchannel Shapes, International Journal of Refrigeration, Vol. 51, pp. 144-153.

Korze'n, A., and Taler, D., 2015, Modeling of Transient Response of a Plate Fin and Tube Heat Exchanger, International Journal of Thermal Sciences, Vol. 92, pp. 188-198.

Krishnakumar, K., John, A. K., and Venkatarathnam, G., 2011, A Review on Transient Test Techniques for Obtaining Heat Transfer Design 
Data of Compact Heat Exchanger Surfaces, Experimental Thermal and Fluid Science, Vol. 35, No. 4, pp. 738-743.

Mishra, M., Das, P., and Sarangi, S., 2006, Transient Behaviour of Crossflow Heat Exchangers Due to Perturbations in Temperature and Flow, International Journal of Heat and Mass Transfer, Vol. 49, No. 5, pp. 1083-1089.

Vaisi, A., Talebi, S., and Esmaeilpour, M., 2011, Transient Behavior Simulation of Fin-andTube Heat Exchangers for the Variation of the Inlet Temperatures of both Fluids, International Communications in Heat and Mass Transfer, Vol. 38, No. 7, pp. 951-957.

Wang, C. C., Chen, K. Y., Liaw, J. S., and Tseng, C. Y., 2015, An Experimental Study of the Air-Side Performance of Fin-and-Tube Heat Exchangers Having Plain, Louver, and Semi-Dimple Vortex Generator Configuration, International Journal of Heat and Mass Transfer, Vol. 80, pp. 281287. 